\title{
Mind-Map-Based POA Enabling Phase Design of an Advanced English Unit
}

\author{
Yin Zhuhui*, Ouyang Yating

\section{Email address:} \\ englishteachers@sina.com (Yin Zhuhui) \\ ${ }^{*}$ Corresponding author
}

School of Foreign Studies, Beijing Information Science \& Technology University, Beijing, China

\section{To cite this article:}

Yin Zhuhui, Ouyang Yating. Mind-Map-Based POA Enabling Phase Design of an Advanced English Unit. International Journal of Language and Linguistics. Vol. 7, No. 5, 2019, pp. 188-193. doi: 10.11648/j.ij11.20190705.12

Received: June 17, 2019; Accepted: July 12, 2019; Published: August 7, 2019

\begin{abstract}
This paper presents the teaching practice of an Advanced English course for English majors within the framework of POA (Production-Oriented Approach), focusing on the various activities in the enabling stage involving mind mapping. The POA teaching procedure, as a holistic loop involving teaching, learning and evaluation, consists of "motivating, enabling, and assessment" phases. In the enabling stage of this study, mind-mapping is used as a supporting device to help students get the structure for their "production" task. For instance, keywords can be written on the mind map branches as a reminder for an oral task, and complete sentences can be produced on the basis of the key words in the mind map. Then with plenty of enabling activities, students get the language and ideas for their tasks. Eventually the structure, the language and the ideas together assist students with their "productions". Preliminary evaluation of the research design received positive feedback, evidence primarily in the form of task samples and learner interviews on the pros and cons of this particular teaching methodology. The meaning of this research rests with its attempt to contextualize a new theoretical framework, a classroom practice guided in a principled way, which, in turn, might generate a variety of insights and interpretations from various aspects.
\end{abstract}

Keywords: POA, Enabling, Mind Mapping, Advanced English

\section{Introduction}

\subsection{Status Quo of "Advanced English"}

At present, the education of college English for language majors, is relatively "monotonous", where the exam is the main baton and the teacher is the center in the classroom. Students have long been used to such a teaching model, lacking independent thinking or autonomy, but featuring a strong sense of dependence on teachers for guidance and compulsory assignments. Most teachers of English majors also favor theory over practice. As a result, students have little practical application skills but substantial difficulty in speaking and writing. This has severely hindered the overall development of students. Problems in the teaching of English majors need to be addressed. First of all, opportunities are not sufficiently available for practical uses of English. Secondly, classroom teaching is still based on language input, and excessive emphasis is on comprehensive reading or listening training. Thirdly, the textbooks do not connect in terms of content and learner levels. For instance, the core course in the first two years "Integrated English" and that of "Advanced English" in the last two year are selected just on a basis of themes. There seems to be no overall design or necessary transition in between, and the curriculum design is not fully integrated with the characteristics of the development of the times and the actual situation of the students.

\subsection{Prospective Advanced English Reform Through POA}

An effective understanding and reasonable execution of POA will help promote reform and development of courses like Advanced English. POA provides new ideas and models for language teaching, like "learning-centeredness", "learning-using integration" and "holistic education" [1]. Such an innovation in pedagogic assumptions implies $\mathrm{s}$ a positive effect on students' comprehensive application ability. In terms of linguistic competence, the course of Advanced English aims rather high: comprehensive English skills and overall literacy, reading strategies and skills, vocabulary and 
grammar, rhetoric and TEM8-level (Test for English Majors, band 8) writing skills. And learners of Advanced English courses are expected to have extensive reading and insightful analysis skills as well as critical thinking on rather long English texts or learning materials in various modes and media. The textbooks cover novels, book reviews, biography, journalism, speeches and other genres, and students read and critique plenty of classic works in politics, society, language, literature, philosophy, etc., with a hope to expand knowledge, deepen understanding of society and life, and cultivate appreciation involved. And through these they can, hopefully, consolidate and improve English language skills as well.

Hence the amount of information in Advanced English is relatively large and vocabulary proves rather burdensome to many learners. The traditional way of teaching is a so-called intensive reading method, which usually leads to the loss of students' initiative in learning and the sense of burnout. At the same time, students' learning efficiency is not satisfactory, and the separation of learning and use is also commonly seen. While the POA theory advocates the combination of learning and using, through the goal of productive use, stimulating input, improving motivation and efficiency. Prospective optimization of the classroom procedure through POA based on contextualized needs analysis therefore, is quite a possible objective for course-level pedagogic reforms.

\section{POA and Mind Mapping}

\section{1. $\mathrm{POA}$}

POA consists of three parts: teaching concepts, teaching hypotheses and teaching procedure (see figure 1). The teaching concepts are: learning-centeredness, learning-using integration, and holistic education. The teaching hypotheses are: output-motivating, input-enabling and selective learning. The teaching procedure includes the motivating phase, the enabling phase, and the assessing phase. Among them, the teaching concept is the guiding ideology, and the teaching hypothesis is the theoretical support. Teaching process is the way to achieve effect [2-3].

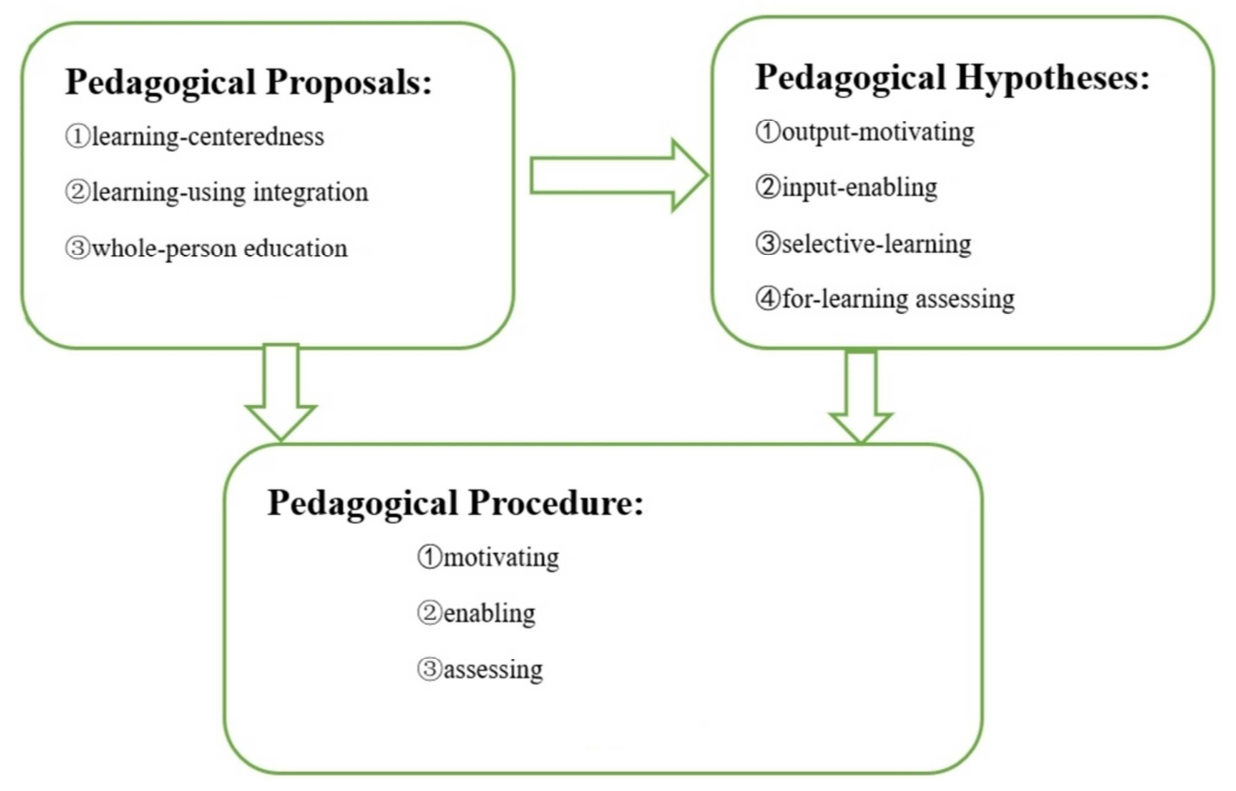

Figure 1. The POA system.

From theorization to actualization, from concept to practice, the teaching of college English (for) English majors in China is faced with reforms in the context of the new era. The POA theoretical system emphasizes the construction of courses and teaching methods that are conducive to students' overall production. This has been gradually applied to the teaching practice of large-scale college English courses and those for English majors. And studies of POA application are increasing year by year. For example, Qiu [4] demonstrates the effectiveness of the POA and the impact of spoken language output. Zhang [5] in the study of the impact of the output-oriented approach on college English writing explores whether there is a significant difference between students' re-writing quality and target language test performance. According to POA, teachers play highly important roles.
Teachers are encouraged to take into consideration of contextual elements at all levels, like national conditions, school conditions, basic situation of students, so as to achieve effective teaching design and improve students' learning effects. POA is of great significance to the reform of college English teaching.

This paper is to focus on the POA enabling phase. The proportion of time in this stage is the largest, and lots of activities are carried out in this phase both inside and outside the classroom. Herein the teacher is the core guide and there supposed to be as many as possible students-teacher interactions. Therefore the guiding role of the teacher is fully exerted, enabling the students to carry out purposeful and selective learning around the production task arranged in the previous stage. Very importantly the production task needs to 
be divided into several sub-tasks for implementation at this stage. Then, the teacher and students work together on a large amount of input so that the students are enabled to intake a lot and practice a lot, scaffolded by various subtasks. And particularly the principle of input is: the content should be relevant, and its difficulty level is appropriate; there should be various approaches and effective tools to enable the students. The media and form of input are expected to be diversified, multi-dimensional and refreshing. The main point is to always keep the input "comprehensible" and helpful to the upcoming production tasks so that learning and production and application can be integrated.

At present, there are not many researches on the design of specific teaching units based on POA theory, and most research is on college English for non-majors. This paper attempts to explore the teaching practice of the Advanced English courses for English majors based on POA theory, focusing on the various activities in the enabling stage.

\subsection{Mind Mapping}

"Mind Mapping" is a tool designed by a British scholar Tony Buzan, which proposes a kind of emissive mind map as a concrete way of thinking. Mind maps involve lines, frames, symbols, images, colors, vocabulary and other elements. At the same time, they use techniques that are well informed to express different levels of thematic relationships, making full use of the skills of the left and right brains, integrating the user's memory, reading, and thinking capacities. Regular presentation of information, combined with this, is beneficial to the processing of information in the human brain.

Mind maps are already applied in undergraduate and postgraduate English teaching. Li and Liu [6-7] start with the motivation theory, combine mind mapping with teaching, strengthen the internal learning motivation of the students, enhance their English cognitive ability, and finally realize the formation of a logical thinking method in students' learning style. Some scholars like He [8], Zhang [9] and Yan [10], have shown that from the perspective of testing, for instance CET-4 or CET-6 (College English Test, Band 4 \& Band6), the examination syllabus requires students not only to have their English ability, but also the ability to think logically. And therein mind mapping can be of great help. Using mind maps, learners could build a logical structure of thinking, grasp the primary and secondary relationships of the content of the English material, and in this way train their critical thinking. Students learn to appreciate the connotation of the English material, endeavoring to explain, analyze, and evaluate so as to improve their comprehensive ability.

In the teaching of English majors, some studies try to apply the mind mapping instrument to vocabulary, reading, grammar and other courses. For example, Zhang [11] proposed to construct a word map through regular construction, which can help to learn and consolidate grammar knowledge, cultivate thinking ability and expression ability. The application of mind maps in Advanced English courses is not yet abundant. This study aims to attempt some experimenting in this aspect.

\section{Research Design}

\subsection{Background}

There are 61 senior students, who are English majors in this study. More than $60 \%$ of the students have passed the TEM4 (Test for English Majors, Band 4). They have a solid foundation in vocabulary and grammar, and they have fairly high confidence in oral communication in English. They face two major challenges. First, there is a huge gap between "Advance English" and the previous "Comprehensive English" while there has been a lack of bridging courses. Many students have reported ideas like these: "the textbook is too thick; the article is too long; the text is too difficult to understand (from the author's questionnaire data)". Secondly, they have the TEM8 goal. The course syllabus describes their language proficiency goals as: understanding and evaluating the deep meaning of academic materials including those in professional fields; accurately grasping the main theme and conducting in-depth exchanges and discussions on various academic and social topics related. Judging from the above goals and the students' actual capacities, it can be said that their production ability is still insufficient and calls for ample training.

\subsection{Teaching Process}

The textbook unit involved in this study is scheduled with 8 sessions altogether, 1 for the "Motivating" stage, 6 for "Enabling" stage, and 1 for the "Assessment" stage of the POA procedure. The textbook is Modern College English Intensive Reading Book 6, and the text title is "The Death of A Pig" written by E. B. White. This paper focuses on and starts with the enabling stage, with the production task as the major teaching objective. It introduces the various enabling activities for the students' production of the sub-tasks. And it also shares some samples produced by the students. Then it tries to evaluate and describe the teaching effect of the enabling stage and summarize the research implications.

\subsection{The "Enabling” Phase Design}

\subsubsection{Mind Mapping for the Structure of "Production"}

Through the organization of elements such as lines, frames, key words and information, the mind mapping tool achieves the role of hierarchical relationship of the theme, making the discourse logical and concrete, e.g., the studies by Wang [12], Abrams \& Byrd [13], Fang, et al [14] and Han [15]. In the POA enabling stage, keywords can be written on the mind map branches, as a reminder for the oral task, and then holistic sentences, both grammatically and semantically, can be brought out on the basis of the key words in the mind map. In other words, the mind map is like a supporting device to help students to get the structure for their task "production" [4]. The students in this study have had the training of Advanced English 1 and Advanced English 2 as well as an Advanced English Writing course, so the teacher doesn't have to give them specific language structures for imitation. They might just try to seek expression structures of their own style and characteristics [2]. And that's where and how mind maps can 
help. The teacher can just recommend some mind map production types or software. The students can complete their own mind maps independently. And then according to the hints of the mind map, they produce their tasks. The mind maps can be drawn manually, or through electronic devices. And the graphs of the mind maps can be varied and creative.

\subsubsection{Abundant Activities for Ideas and Language of "Production"}

The overall task of this unit is to retell the story or review it (description, explanation, or argumentation). Whether to retell or review, students are required to express with a rich content, in clear, appropriate forms reflecting their competence in language, culture and thinking. This kind of production task is similar to literary criticism, which is challenging in terms of "content" even if it is done in the students' mother tongue, Chinese. So the biggest difficulty for the students is: what ideas to express in their retelling or reviewing of the story. And once they get the ideas, language forms are not such a big problem for them. In order to obtain the effectiveness of "enabling", this study designed a "package" method. That means the content resources and language resources are closely combined. And students can review or retell the story from different aspects. Whatever aspect they choose, they have the opportunity to be enabled by some activities. For example, if they want to review the story in terms of its "theme", then there would be different activities for them to take part in. They could (see also A2-2) (1) listen to the teacher's instruction on "the theme of the novel"; (2) they could analyze the theme of a previous text, Alice Monroe's Nettles, and then find the theme of the new text, which is about the death of the pig, and about all life and death; (3) they could listen to music: The Eternity of Time; Life and Death; (4) they could watch a videoclip entitled Life is Short; (5) they could have a pair discussion on the relationship between love and loss, mortality and eternity; or (6) they could get a lot of materials related to the topic by self-learning after class. For another example, if they choose the story-retelling task, they could (1) listen to the teacher's instruction on "the plot of the novel" and get to learn some key terms and concepts such as "exposition", "the rising action", "climax/crisis", "the falling action", "denouement/resolution", "chronological, "flashback" etc.; (2) watch a short movie entitled "Wat's Pig" so that they can understand how to retell a story according to the stages in plot development; or (3) they could have a pair discussion on a previous text Two Kinds by Amy Tan, and then compare the previous text with the new text in this unit and decide whether to retell the story in a chronological way or with flashbacks.

Such a package of information and activities gives the students sufficient raw materials needed for their "production" (as is targeted in the Production-oriented approach). It gives the students the opportunity to interact with the teacher and other students. At the same time, it helps the students to produce their story reviews in line with the discourse norms, closer to the real "communicative" standard [16].

\subsection{Enabling Activities Design}

First, the overall production task of this lesson is either to retell or to review the E. B. White story. And the story-retelling task is divided into two subtasks. They are marked as T1-1 and T1-2. The story-reviewing task is divided into 6 subtasks. They are marked as T2-1 to T2-6. They are all oral tasks. Altogether students have 8 choices/tasks, from which each student could select one to fulfill. Different students choose different tasks. The teacher organizes activities to enable the students to finish their tasks. The students will go through all the activities but they would put emphasis on the chosen-task-related activities. The enabling activities are marked, according to the sub-tasks, as A1-1, A1-2, A2-1 to A2-6.

Students participate in all enabling activities; they select one subtask based on what they are interested in or good at. Then they take part in the enabling activities. And then they complete their "production". There is also a derivative task, Tw (writing). All the students are required to fulfill the writing task and give a written "production".

The enabling activities go as follows. Note that the task is to "produce" an oral or written discourse in the form of retelling the story or reviewing the story. But in order to enable the students, the teacher uses a lot of questions. Hopefully in the process of thinking about and trying to answer those questions, the students would gradually be able to produce the task.

T1-1: Please analyze the five stages of plot development in E. B. White's story, commenting on the effect of events order, which is chronological.
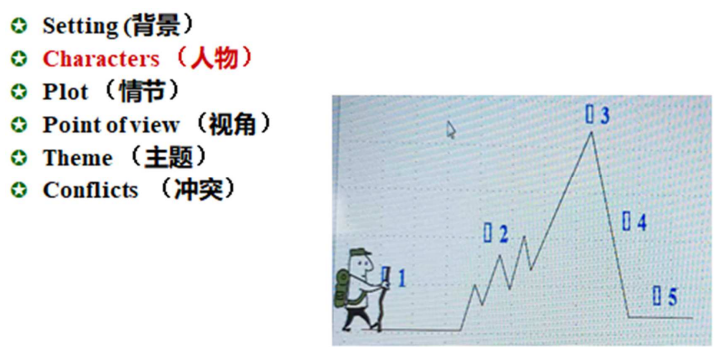

Figure 2. Elements of A Novel \& Plot Development Stages.

A1-1: (1) instruction on "the plot of a novel"; (2) reviewing a previous text, Amy Tan's novel (excerpt) Two Kinds, in terms of its plot development; (3) pair discussion: the plot of the story in this unit, trying to use the key terms to describe plot development, such as "exposition, the rising action, climax/crisis, the falling action, denouement/resolution, chronological, flashback". The teacher's instruction is supplemented by diagrams (see Figure 2), and through question-and-answer interaction, students are encouraged to keep thinking and begin the "internalization" process as soon as possible.

T1-2: Please retell the story of White's pig, events in time sequence or as a series of flashbacks. The story of Wat's Pig is for your reference in terms of plot development.

A1-2: (1) Watch the video, Wat's Pig; (2) pair discussion: time line of the story's development. 
T1-1 and T1-2 are proposed from the perspective of the storyline or narrative sequence. The difficulty level is moderate and such a task is placed in the beginning of the task list, hoping to achieve an effect of progressive difficulty.

T2-1: please review the description of the gloomy, saddening weather of the burial scene.

A2-1: (1) instruction on "the setting of a novel"; (2) reviewing a previous text, Faulkner's $A$ Rose for Emily, in terms of its setting; (3) pair discussion: the description of the burial scene or the day of the death of the pig in this unit.

T2-2: Please compare White's attitudes toward his pig between the beginning and the end of the story and comment on the philosophical or spiritual values revealed when White's pig died.

A2-2: (1) the teacher's instruction on "the theme of the novel"; (2) students analyzing the theme of a previous text, Alice Monroe's Nettles, and then finding the theme of the new text, which is about the death of the pig, and about all life and death; (3) listening to music: The Eternity of Time; Life and Death; (4) watching a videoclip entitled Life is Short; (5) pair discussion on the relationship between love and loss, mortality and eternity; or (6) reference to a lot of materials related to the topic by self-learning after class.

T2-3: Discuss in pairs the relationship between human beings and animals. Take for instance your pet, if any.

A2-3: (1) group discussion: analyzing the narrator's feelings towards the pig, from meat-eating, to friends-like feeling, to the development of a family-member sense. (2) Watching the video, Talent Show of A Genius Pig. (3) Pair discussion: the experience of keeping pets and how to treat animals.

T2-4: Please analyze the role of the dog, Fred, noting that he is active and delighted while visiting the ailing pig.

A2-4: (1) the teacher's instruction on "characters and conflicts of a novel"; (2) group discussion: the metaphorical role of the conflict between the pig and the dog in the story. (2) pair exercises: an example of conflicts between yourself and others, or yourself with the environment, or the conflict between you and your inner world.

T2-5: E B White is called "a humane humorist". Please find examples from the text to support this point.

A2-5: the teacher's instruction on E B White's experience, works, achievements, styles etc., combined with such stories as "Stuart Little" and "Charlotte's Web".

T2-6: Please cite examples of allusion, parallelism, imagery, metaphor, epiphany, empathy, parody, and personification from within/without the text.

A2-6: (1) students read the text (including the guidance reading part) on the content of rhetoric;(2) the teacher's instruction on examples of rhetoric devices like metaphor, allusion, epiphany, empathy, imagery, personification and so on. (3) self-learning after class: other examples of the above rhetorical devices.

$\mathrm{T}_{\mathrm{w}}$ : 2019 is coming. Please reflect on the past year, write a year-end summary and a new-year plan.

Aw: (1) reviewing one of the themes of the lesson, "Time is eternal and life is short". (2) unit summary, reviewing the content of the "motivating" stage: George W Bush's speech at his father's funeral, on December 4, 2018; (3) pair discussion: what did you do and learn in the past year? What is your new year plan?

\section{Preliminary Evaluation the Research Design}

\subsection{Production Samples}

As is shown in the following picture (figure 3), after selective learning, the students first produce mind-maps, and then they produce oral reviews or retellings of the story based on their mind maps. The characteristics of their productions are different in terms of content, language and structure. Some choose to the review of "key elements of a novel"; while some focus on "themes" or "the plot"; and still some care about rhetorical devices. Their mind maps are individualistic. The content of the spoken products P1-1 to P2-6 are also different based on varied mind maps. And the depth and quality of the language in students' productions also vary a lot. For example, regarding the theme of the novel, some productions are simple and clear: "Life is short." "Every life is valuable". But some talk about "the relationship between human being and animals" in great details. And for the same idea of life being limited, some use the word "short" while some use "transitory". Regarding the plot of the novel, some of the productions are more generally organized, just giving the names of the five stages; while some try to sort out the original story and re-arrange it in a chronological order. With regard to rhetorical methods, some produce a sentence using the allusion to "Achilles' heel"; some produce a sentence saying that "Opportunity is knocking at his door." The writing task produces rich content. On some branches of the mind maps, complete sentences or even sentence clusters are written (instead of merely key words). It can be said that the students' language knowledge and skills, critical thinking ability and intercultural communication ability are trained and displayed.

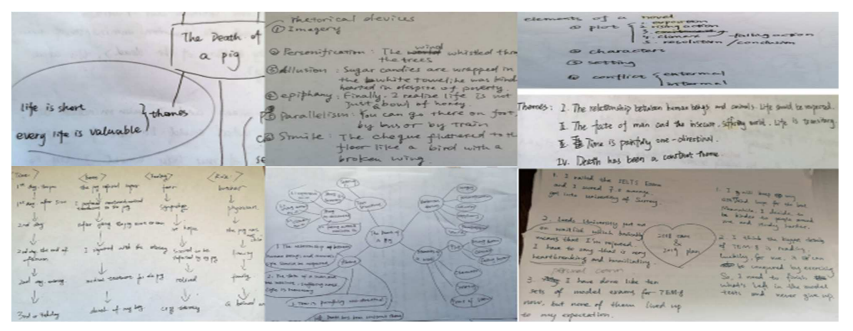

Figure 3. Students' Production Samples.

\subsection{Students' Feedback}

First, the overall evaluation is positive. There is a lot of such feedback: "the amount of my reading is increased"; "my horizon is expanded"; "I learnt a lot of discourse analysis methods"; "I master a lot of new words"; "I have a deeper understanding of the article"; "the biggest gain is logic"; "The development of thinking is obvious"; "I know now writing is not a matter of casual work, but justification, logic, and 
structure."

Secondly, there are different voices. Some comments and suggestions (see figure 4 below), for example, indicate the limitations of this research design: "the amount of tasks is a bit huge"; "the knowledge points are overwhelming"; "the amount of tasks can be reduced appropriately"; "some part of the course should have been assigned in the (previous) junior year" and so on.
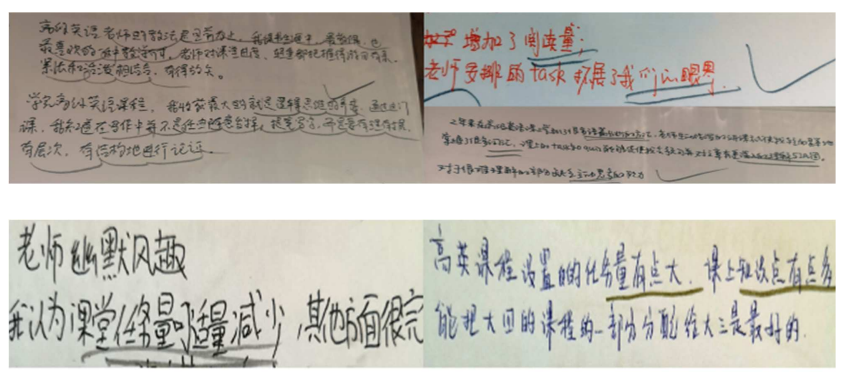

Figure 4. Students' Feedback Samples.

\section{Conclusion}

This paper presents the design and actualization of a classroom practice guided by the POA theory. It focuses on the enabling phase, which takes up quite a few teaching hours both within and beyond the classroom. Therein the teacher can play the role of designers and organizers to enable the students to produce a lot. And the students can selectively learn about topics, ideas, cultural information, language expressions, discourse structures, language communication aids (such as mind mapping) etc. The POA teaching exploration in this study gets some positive feedback. But there are limitations and problems at the same time. That leaves space for future research and experiments. Insights and interpretations might emerge on the basis of this experimental study, with view to themes such as contextualized pedagogy, teacher role and teacher identity in a reform-oriented landscape of language education in China.

\section{References}

[1] Wen, Q. F. (2016). The Production-Oriented Approach to Teaching University Students English in China. Language Teaching (4): 1-15.
[2] Wen, Q. F. (2015). Establishing POA Theoretical System. Foreign Language Teaching \& Research. (4): 547-558.

[3] Wen, Q. F. (2017). Chinese Characteristics in POA. Modern Foreign Languages. (3): 348-358.

[4] Qiu L. (2017). Process Design of A Language-Focused POA Enabling Phase. Modern Foreign Languages. (3): 386-396.

[5] Sun S. G. (2017). Researching POA Teaching Material: Production Objective Design \& Assessment. Foreign Language Education in China (2): 24-31.

[6] Li J. (2014). Motivation Theory, Mind Mapping and College English Vocabulary Acquisition. Journal of SanXia University. (06): 212-213.

[7] Liu X. (2019). Mind Mapping for College English Teaching from the Graphic-Textual Perspective. MA Thesis: Ocean University of China.

[8] He L. J. (2017). Mind Mapping in China's College English Education. Cultural and Educational Materials (26): 226-227.

[9] Zhang. W. J. (2016). Teaching Practice of A College English Class Based on POA. Foreign Language Teaching \& Research. (2): 106-114.

[10] Yan S. X. (2016). Mind Mapping: A New Route to Optimizing Classroom Teaching. Education Science. (03): 24-28.

[11] Zhang L. Y. (2016). An Experimental Study on Mind-Map-Based College English Reading Promotion. Library Research and Practice. (03): 13-17.

[12] Wang J J. 2014. An Empirical Study on the Effectiveness of the Mind Mapping in English Majors' Reading Comprehension. MA thesis. Shenyang: Shenyang Normal University.

[13] Z. I. Abrams \& D. R. Byrd. (2016). The Effects of Pre-task Planning on 21 Writing: Mind-mapping and Chronological Sequencing in a 1st-year German Class. System, 63: 1-12.

[14] Fang. F., Zhang J., Zheng. A. S. (2018). Mind-Map-Based Critical Thinking Ability Cultivation in Postgraduate English Education. Journal of Mudanjiang University (02): 141-144.

[15] Han Y. F. (2018). Reform \& Exploration in Practical Teaching of English Major Based on POA. Journal of Jilin Radio and television University (6): 132-133.

[16] Widdowson, H \& Seidlhofer, B. (2018). POA and Issues of Pedagogic Principle. Chinese Journal of Applied Linguistics (41-2): 238-240. 